\title{
Research on Enlightenment of Supply - side Structural Reform on the Development of Chinese Old Sports Industry
}

\section{Songzhong Ye}

Public Sports Ministry, Fujian Jiangxia College, Fuzhou, 350108, China

\begin{abstract}
Keywords: Supply-Side Structural Reform; Elderly Sports Industry; Structural Optimization.
\end{abstract}
\begin{abstract}
The development of Chinese elderly sports industry is the process of optimizing and upgrading and rationalizing the structure of the sports industry. First of all, the paper analyzes the structural contradictions in the old-age sports industry, such as the huge demand-side market gap and the insufficient supply side of the senior sports industry. Secondly, the significance of structural reforms in the supply side of the aged sports industry is to promote the long-term sustainable development of the aged sports industry, highlighting the role of resource allocation in the elderly sports market, balancing the development and layout of the sports industry structure in the elderly and reshaping the logic system of the sports industry structure in the elderly. Finally, it put forward that innovation should serve as a primary motivation for the supply side of the elderly sports industry. As the core of optimizing the structure of the sports industry in the old age, it is necessary to grasp the deep integration trend of the supply side of the sports industry in the old age, and construct the policy pillar of the optimization of the industrial structure of the sports industry in the aged as the inspiration for optimizing the structure of the sports industry in the aged.
\end{abstract}

\section{Introduction}

The history of the economic development of various countries in the world proves that the stage where a country moves from a middle-income to a high-income is exactly the most dramatic change in the industrial structure. Under the circumstance that the Chinese economy is facing a series of new prominent contradictions and entering a new normal, the development of the aged sports industry will inevitably face a structural imbalance. Although the State Council issued "Several Opinions on speeding up the Development of Sports Industry and Promoting Sports Consumption" in October 2014, it clearly stated that "promoting the integration of sports and pension services" has pointed out the direction for the development of the sports industry for the elderly [2]. However, due to the monotony of old-age sporting goods in China, the scarcity of species, the sports services and the shortage of sporting goods, which are unique needs of the elderly, the "dislocation of supply and demand" has become one of the most prominent problems in the development of the sports industry in the elderly. There is a demand market, to develop the sports "silver market", stimulating the consumption of the elderly, we must understand the main sports consumer market needs and characteristics [3], such as the majority of older people with realistic, cost-effective frugal value Oriented, then sports products should be catered to this value orientation of the elderly. Therefore, taking the supply-side structural reform as a breakthrough, starting from the provision of elder sports service and product manufacturing and supply and adjusting the supply structure of the elder sports industry, it provides an effective path for building the new impetus for the development of the elder sports industry and actually launching domestic demand. In the context of the national economic regulation shift from "demand side" to "supply side", for the aged sports industry, supply-side structural reform is a rare development opportunity. Faced with the new situation, how to integrate the supply chain structural reform strategy into Chinese elderly sports industry seize the opportunity of reform to optimize the industrial structure of the elderly sports and improve the productivity of enterprises so as to achieve leapfrog development. The discussion of these issues is not only a theoretical study, but also a practical issue for us to correctly handle the development of the sports industry for the elderly. It is of great significance in guiding and promoting the development of the sports industry in China. 


\section{The Senior Sports Industry Structural Contradictions Predicament}

With the improvement of people's living standards and economic development, fashion is no longer the patent of young people. The concept of consumption of the elderly has changed, the pursuit of sports, fitness fashion, the elderly are increasingly diverse and demanding physical fitness Levels continue to improve [4]. The consumption type of demand side of the elderly sports industry began to shift from the consumption of basic sports for the elderly dominated by monotonous, middle and low-end sports products and services to the consumption-oriented and personalized sports consumption, as well as more emphasis on products and services The experience of the value and quality of development of sports consumption. Through the gear shift upgrade, the market for the demand side of the aged sports industry has gradually entered the period for innovation and innovation, while the stage for the aged sports development has not been adapted to the market side of the demand side. The two major aspects are as follows.

First, elderly sports products cannot be effectively supplied. Under the new normal economic development in China, the possibility of using old-age sports products with demographic dividend to realize the lower cost advantage of natural resource-intensive and labor-intensive products is gradually decreasing. However, the possibility of occupying market shares solely based on factor endowments or comparative advantages may be reduced Sex is also gradually reduced. Under such circumstances, low-end supply, vulgar supply, excess supply, sluggish supply and zombie supply squeeze the sports "silver market", the backlog of enterprise products, and the surplus of low-end products. Elsewhere, however, the demand for high-tech, high-quality sports goods has been rising but not yet being produced. Sports "silver hair market" not only lack the widely recognized fist products and masterpieces of quality, but also lack the quality and cheap mass sports products for the elderly. Many sports products suffer from cold reception in the consumption segment of the elderly and the market value they deserve is hard to obtain.

Second, the original lack of original sports products. Looking at the current content of Chinese elderly sports consumption, overall monotonous, lack of original power, the low level of the elderly sports product market homogeneity serious, forming a competitive reproduction, the way of development is still extensive. Due to lack of outstanding creativity and lack of originality, the sports "silver hair market" lacks innovative products that are widely accepted by the elderly consumers. With the growing demand of the elderly for sports consumption, the demand for sports products is also getting higher and higher, while the quality of the sports products for the elderly is not effectively improved in time. This leads to the structural contradiction between the supply and demand of senior sports products and the willingness to spend cannot be converted into consumer behavior, it is difficult to meet consumer demand.

According to the China Development Report on the Aging of Chinese First Older Industries (2014), the blue book on Chinese first development of aging industries shows that from 2014 to 2050, the consumption potential of Chinese elderly population will grow from about 4 trillion yuan to about 10.6 billion yuan, accounting for the proportion of GDP Will grow from about $8 \%$ to about $33 \%$, making it the country with the largest market potential in the global aging industry [5]. The elderly sports industry is not only the elderly sports products, sports services, sports culture and other broad space for development, the demand-side market there is a huge gap. In fact, the consumption of sports products and services on the consumer side of the elderly population in China is still at a relatively low level, both in terms of the consumption demand of the elderly who are continuously expanding and the rate of industrial growth. This is in line with the fact that the current consumer market for the elderly is shifting from tangible sports products Changes in consumer demand for sports services, from the satisfaction of the past to improve the quality of the transition from the mimic wave-type consumer diversification and diversification of individual consumption change and the overall pattern of change is not consistent with the requirements.

Corresponding to the huge gap in Chinese elderly sports consumer market, there are unreasonable institutional and structural elements in the supply side of Chinese elderly sports products and services. As Chinese urbanization releases consumption and stimulates domestic demand, the elderly are more diversified in their demand for sports consumption. While paying 
attention to the equality and inclusiveness of the demand for basic sports services for the elderly, The form and content of services put forward deeper requirements, and the characteristics and geriatric supply of sports services in the elderly are characterized by local conditions. However, corresponding to the elastic development of sports demand for seniors, the elderly-oriented sports products and services on the supply side are single and stereotyped, so it is difficult to meet the experiential and diversified enjoyment and development-type sports consumption needs of the elderly. In the supply side field Performance can be attributed to two aspects.

First, supply constraints and supply constraints co-exist. Due to the high degree of concentration of Chinese sports management system and the administrative industry monopolizes the sports industry. The emergence of administrative monopolies has resulted in the enlargement of market access conflicts in the sports industry. As a result, the sports industry has become a dilemma of market failure and government failure. Since the mid-1990s, sports industry groups such as sporting goods, sports tourism, sports architecture and sporting advertisements have been set up in some regions of China. The original intention of these sports industry groups was to "improve overall efficiency and aggregate multiple capabilities" and achieve "Optimize the allocation of resources, clean up the stock of resources," but the formation of these sports industry groups are often dominated by the government, the market's role in the allocation of resources is replaced by the role of government power, the government aborted the sports industry in the planning arrangements As the core role of innovation subject, the social sports capital has its own strength as the main body of the market, but it is hard to realize the all-round innovation of the factor structure in the elderly sports industry with creativity as the core. From the perspective of global economic integration of sports and from the perspective of comprehensive and dynamic development, the long-term development of the aged sports industry is constrained. The structural reform of the elements of the aged sports industry urgently requires the supply-side structural reforms.

Second, the lack of targeted supply policy. Some problems existed in Chinese senior sports industry policies include poor operability of policies, uncoordinated policies, weak policies, lack of focus, lack of continuity and stability of policies, weak policies and measures, lack of support and lack of policies Wait. To be specific, policymaking on the sports industry in the elderly is often a one-size-fits-all approach and it is difficult to take full consideration of the large regional disparities in the development of the sports industry in the elderly and the differences in the characteristics of different industries in the aged sports industry. At the same time, the phenomena of weak legislation and lack of policies still exist. The policy support and protection of the old sports industry is weak and lacks continuity and stability. The legalization, democratization of the decision-making process of the aged sports industry are hard to be improved, and the institutional structure of the aged sports industry urgently needs supply-side structural reform.

While there is still some room for optimization and improvement in traditional demand management, efforts should be made to improve the supply environment for aged sports products and services by optimizing the supply-side mechanism of the aged sports industry so as to create new supply and lead the release of new demand so as to stimulate the market for the aged sports industry main vitality, remodeling and strengthening the elderly sports industry sustainable, long-term growth of new impetus imperative.

\section{The Significance of Senile Sports Industry Supply-Side Structural Reform}

From an economic point of view, the "troika" on the demand side is the demand-side power to cope with macroeconomic fluctuations and is based on the results of operations. It is convenient for macroeconomic regulation and control to carry out short-term counter-cyclical adjustment instead of driving force for development. On the other hand, the supply side starts from the source of operation and seeks to achieve its more prominent long-term transformation and upgrading based on the fundamental and sustainable motivation of system reform, structural optimization and factor upgrading [6]. With the continuous expansion of the channels and carriers for the development of the aged sports industry in China, the optimization and upgrading of the aged sports industry structure have been transformed into long-term tasks. The structural reforms in the supply side of 
the aged sports industry reflect the changes in the quality and development benefits of the elderly. Therefore, in the optimization of the supply side of the old sports system and the elderly sports ecosystem, through the open market space and efficient system of supply, to stimulate the micro-sports industry in the main body of the micro-creation, entrepreneurship, innovation potential to better shape, build and strengthen the new impetus for the long-term growth of the aged sports industry and achieve the sustainable development of the aged sports industry.

In the past, we emphasized too much on the role of the government in macro-control from the demand side. The visible hand intervened too much and stretched too long. The essence of the supply-side reform is to handle the relationship between the market and the government and make the market play a decisive role in the allocation of resources. Supply-side structural reform through technological innovation and institutional innovation to improve business development capabilities, reduce business costs, increase the effective supply of senior sports products and services, through the decentralization of power, so as to better activate the micro vitality. The structural reform on the supply side of the aged sports industry takes the sports entrepreneur and the sports enterprise as the main characters and takes the elderly as the creative stratum to get rid of the old-age sports products and services under the premise of ensuring double-effect and unity of the aged sports products and services and upholding the socialist core value system At present, the supply constraints and supply restraints that restrict the development of Chinese elderly sports industry are restrained. The role of the market is further strengthened by creating high-quality sports elements and ecological innovation for the elderly, and the expansion of the effective supply of the sports industry for the elderly in the end is better.

The reform of supply-side structural reforms is to introduce the macro-control into the macro-control and significantly optimize the macro-control environment. The reforms emphasize the long-term benefits and the present, long-term and short-term adjustment and control of the timeline, Form a "short-term + long-term" thinking. As the senior sports products and services from order processing to simple imitation, from imitation to the original, the elderly sports industry structure continues to achieve a high degree of rationalization, but the elderly sports industry has the special ideological attributes of the elderly, therefore, the elderly sports industry Cyclical fluctuations exist in the non-public sports economy and the government together to create counter-cyclical strength, under certain conditions, these two counter-cyclical forces may have a significant impact on the elderly sports industry growth cycle curve movement. In addition, due to the differences in economic development in the eastern, central and western regions of China, the structure of the sports industry in the elderly is quite different. In the process of reshaping the industrial structure of the aged sports, it is inevitable that a middle-income trap will be encountered. In order to increase the potential growth rate, institutional and structural changes must be taken before the long-term and short-term development of the aged sports industry can be effectively combined.

From the perspective of changes in the structure of the sports industry in the elderly, in terms of production, the supply-side structural reforms will lead to an increase in the share of emerging industries in the secondary industry, a decline in the proportion of traditional industries and a rise in the proportion of tertiary industries. This fully shows that the development of the aged sports industry is in line with the concept of "sharing, opening up, greening, coordinating and innovating" and can also be in line with the development characteristics of the aged sports industry. The structure of the aged sports industry leads the structural reform of the supply side under the changes that will effectively promote the development of the elderly sports industry. From a revenue perspective, the reason for the increase in the proportion of corporate operating surpluses is the reduction of production capacity and costs, which will increase human capital and speed up cross-regional labor turnover. As a result, workers' remuneration will rise and supply-side reforms will trigger Re-distribution of economic cake. Consumer's leading power is more abundant, demand of elderly sports products and services as enjoyment-type and development-type consumption will be more fully. Therefore, the effective supply which can provide strong driving force for the optimization of industrial structure of the aged sports is the supply-side reform. 


\section{Thinking of Supply Side Structural Reforms on Optimize the Structure of the Elderly Sports Industry}

Factor innovation is the source of innovation in the supply side reform of the aged sports industry. From the supply side, five sources of power, capital, natural resources and land, labor, innovation and system, are the elements that support long-term economic growth. International experience shows that the contributions of capital, natural resources, land and labor to economic growth have been reflected in the various economies before they enter the middle-income category. Therefore, when emphasizing the extensive development and the input of factors, the general economy is the initial stage and the take-off stage of their development. After entering the middle income, the innovation and system are extremely crucial and contribute more. With the development of Chinese economy, in the new stage of transformation and upgrading, the current production structure and institutional structure have been unable to meet the new needs of individualization and diversification of middle-income families, which is not conducive to the release of the reform bonus and consumption potential and innovation The supply-side reform of the elderly sports industry as the core power is imminent.

The innovation of sports industry governance model is the innovation basis for the supply side reform of the aged sports industry, that is, the social, economic and political value conversion of senior citizens' sports is carried out in the form of market economy so as to reshape and change the state governance model. The characteristic of sports industry governance is the paradigm of actively seeking a kind of creative sport hyperplasia in order to realize the inclusive development of sports [8]. The first innovation of system reform for the supply side of aged sports industry is that the government, through the effective innovation of social and economic management, breaks through the unfair pricing power of interest groups to the aged sports market to the maximum extent and forms the national senior people's sports management system and fully activates Release the justice and fairness of the elderly sports market. Fully release the vitality of development of social economy and realize the all-round development of sports "silver hair market".

Science and technology innovation is the innovation wing of the supply side reform of the aged sports industry. Innovation is the essence of science and technology[9]. In the age of knowledge-based economy, both scientific and technological knowledge can form a new industry, products can be infinitely valued, and at the same time an important resource, and scientific and technological innovation has become an important force in promoting social development. The current demographic dividend in China, labor costs, science and technology innovation is an effective means to solve this problem, but also to reduce the cost of the elderly sports products and services an important factor in the elderly sports industry, if accompanied by technological elements of productivity, the "multiplier will certainly be able to achieve rapid and efficient development.

Expand Effective Supply to Optimize the Structure of Senior Citizens Sports Industry. The variability and limitlessness of human consumption demand have promoted the continuous development of society. Consumption demand can be regarded as the source of power. However, in the long run, consumer demand is not the most important support factor, but the guidance and response of effective supply to consumer demand. The overcapacity in essence is the product's competitiveness is not strong, low quality, that is, product structure. China is the largest sporting goods manufacturer in the world, but the sporting goods industry has serious invalid supply [10]. For example, Beijing hosted the Great Leap Forward in the sporting goods industry during the Olympic Games, resulting in overcapacity, resulting in a high stockpile of the entire industry. Since 2011, the sporting goods market has bottomed. ANTA's annual report shows that from 2011 to 2014, the number of corporate stores decreased from 8,665 to 7,622, accounting for $12.04 \%$ of the total. The total number of closed stores was 1,043. How to clean up excess inventory, ANTA is an important measure taken in product development, increase market research efforts, the company take the initiative to understand the needs of consumers, including the elderly sporting goods, and strive to develop products that consumers really need. This highly marketized mode of operation is exactly the mode innovation of expanding effective supply and optimizing industrial structure.

The consumption structure of Chinese residents has undergone "wave" changes along with the 
reform and opening up. The transformation of traditional industries based on the corresponding new economy, new formats, new models and "Internet + " has jointly driven the shift of sports consumption to more yuan and Richer spiritual product and service phases. To develop the new sports industry for the elderly, we can optimize the structure of the sports industry for the aged by means of effectively providing the demand for sports consumption of the elderly, creating new supply, fostering new demands in the elderly sports market. For example, the United States has made painstaking efforts to achieve economic recovery and economic growth through innovation through the supply-side reform since the financial crisis in 2008. For example, to achieve the re-industrialization (Industrial Internet), to promote shale gas energy revolution, created the Apple mobile phones. Therefore, vigorously developing the emerging industries is a distinctive feature of the supply-side structural reforms. Emerging industries have created new materials, new technologies, new products and new markets, have released new demands and created new supply.

Create Active Supply with "Elder Sports +". Old-age Sports + is a vertical and horizontal combination of industries led by old-age sports. It focuses on improving the efficiency and quality of old-age sports products and service supply systems to create new supplies, meet new demands, provide new models for the development of elderly sports, New ideas and new formats. The integration of "Elder Sports +" mainly includes innovating the sports innovation products and services for the elderly, rebuilding the traditional elder sports industry, increasing the scientific and technological content of the elder sports products and services, enhancing the factor utilization rate and promoting the integration of elder sports science and technology; Promote the innovation of the elderly sports financial products and services by innovating the capital system; innovate the forms of the elderly sports financial services organizations and the management of the assets of the aged sports assets; promote the integration of elder sports and finance; promote the elder sports travel products and services in a branding and quality manner Innovation, to enhance the development of sports souvenirs for the elderly to enhance the development of sports tourism in the elderly and the depth of the content to promote the integration of the development of sports tourism in the elderly; image licensing and creative design as a guide to promote innovation in the elderly sports manufacturing industry to speed up the old sports fitness elements Integration into manufacturing design, R \& D and other high-end links in the value chain, extension to service model upgrading and design services, and promotion of the integration of senior sports and manufacturing industries. To promote the integration of elder physical education with geriatric physical education linkage and with the linkage of industry, university and academia; To promote the integration and development of elder-age physical fitness and elder fitness community with integration to promote the integration of elder sports with healthy China and leisure China; Using Internet as Carrier to Promote the Integration and Development of Senior Sports Logistics.

Innovative and Effective Supply Channels with "Internet +". The so-called "Internet +" refers to the Internet to promote integration with any other industry to promote efficiency. "Internet +" senior sports, solve the direction of the reform of the supply side of the elderly sports industry, the elderly sports products and services do not meet the diversified needs of consumers changes, the fundamental reason is not to keep up with the trend of the times, and affect the social economy The biggest trend of development is the content of "Internet + ". The essence of "Internet + " relies on network technology and information infrastructure to realize the mutual sharing and interoperability of resources and information. "Internet +" is a systematic project that should guide more Internet enterprises to embark on the path of pursuing high added-value and science and technology innovation. Remember that one-way application thinking focuses on overall planning, top-level design, and system layout to achieve a comprehensive promotion.

Long-term and long-term macroeconomic policy is an important guarantee for the sustainable development of the elderly sports industry and can create a stable economic environment for the elderly. Supply-side reform is a long-term task. From stressing demand-side management to emphasizing supply-side reform, it is precisely the economic work train of thought that emphasizes the transformation of short-term economic growth to emphasizing the benefits and quality of economic growth and emphasizing sustainable development. For the development of the sports 
industry in the elderly, we should supply with an open market space and an efficient system to reconstruct and create the long-term driving force for the development of the sports industry in the elderly in optimizing the supply-side environmental mechanism. From the perspective of macro-control policy, we must take the dynamic and long-term as the basic requirements, taking the speed of industrial change and global knowledge updating as the basic requirements, emphasizing starting from the source of the aged sports industry, raising the industry's span, depth and breadth, From the perspective of enterprises and industries to solve the middle-aged sports industry in the development of deep-seated problems, so as to highlight the long-term upgrading of the sports industry in the elderly transformation.

The micro-policies tailored to local conditions are the essential requirements of supply-side structural reforms. Through the adoption of micro-policies and decentralization and decentralization of power according to local conditions, we can activate the active role of the elderly sports entrepreneurs and enterprises in stimulating the consumption potential and vitality of the elderly. The purpose of the micro-policies is to guide the market behavior, make up the market failure, systematically optimize and adjust the talent, environment, land, investment, finance and taxation policies of the aged sports industry, and form the knowledge that is conducive to the coordinated development of the aged sports industry upgrade and elderly sports consumption upgrade. Flexible and multi-level knowledge network is conducive to the sharing of knowledge among the elders of the sports industry. Creative collision creates an atmosphere of innovation among the creative sectors to create a creative space for the new sports industry format, new models and new product development. Support, make enterprises have more innovative ability.

The industrial policy that can be landed is an important path for the aged sports industry to solve the "mismatch between supply and demand." Industrial policies can be promoted by building bridges between top-level design and grass-roots implementation. The basic premise of maximizing the role of policy is to effectively bring the policy in line with the actual situation. Therefore, the industrial policy should focus on optimizing the structure of the sports market for the elderly and starting from the basic rules of the sports industry for the elderly to improve the efficiency of the development of the sports industry for the elderly. It is noteworthy that the correct treatment of the lag time of the arrival of the policy and the strengthening of the guarantee and incentive mechanism for landing are crucial to the supply-side structural reform of the elderly sports industry focusing on the long-term development. Each industry has its own characteristics of the industry, different regions have different resource endowments, which makes the formulation of the implementation details, the need to delay the landing according to the actual situation may be caused should be treated correctly. However, in this process, we should gradually reduce the possibility of lazy governance and clearly define the monitoring mechanism for the arrival of policies.

\section{Conclusions}

On the one hand, the supply side reform of the aged sports industry is to allow the market to promptly clear the market, activate "sluggish" supply, clean up the supply of "zombies", eliminate excess supply, reduce low-end supply, eliminate vulgar supply and cultivate new economic growth points; on the other hand, Aspects are the effective supply of higher quality older sports products and services based on innovation, in short, the devaluation of bad money. With the reform of the supply side of the aged sports industry, the coordination, interactivity and integrity of the reform and innovation of the aged sports will be increasingly enhanced. The development of the aged sports will usher in a substantive change. The span, intensity and breadth of the integration of the aged sports industry will continue to improve. Of course, supply-side structural reforms will not only increase the supply of domestic demand, but also increase the level of supply in the international market. The main body of the market for the aged sports industry will create and explore a new way to promote and inspire the sports for the aged through continuously innovating the management mode, innovating the content form, innovating the organizational form, innovating the old-age sports fitness concept and taking supply side as the starting point. And produce a more vigorous and effective supply of production path, so as to "Sports Power" to inject new strength. 


\section{Acknowledgements}

Fund Project: Sports Philosophy Social Science Research Project of the State Sports General Administration (Project Number: 2315SS16052).Fujian Provincial Social Science Planning Project (Project Number: FJ2016B165).

\section{References}

[1] Guan Lijie. "Middle Income Trap" and Chinese Economic Development Strategy [D]. Jilin University, 2013, (6): 32.

[2] State Council (Guo Fa [2014] No. 46). Opinions on Accelerating the Development of Sports Industry and Promoting Sports Consumption [Z] .2014.

[3] Hu Jingchao. Chinese Elderly Quality of Life Patterns in China [D]. Hebei Normal University, 2015, (5): 45.

[4] JIN Zaihuo, Wang Shuxia, Sun Bin. Survey and Analysis of the Status Quo of Chinese Elderly Sports Consumption in the 21st Century [J]. Journal of Beijing Sport University, 2006, (12): 1639-1641.

[5] Wu Yushao, Dang Junwu. Chinese aging industry development report [M]. Beijing: Social Sciences Academic Press, 2014: 09.

[6] National School of Administration. Chinese supply-side structural reform [M]. Beijing: People's Publishing House, 2016: 01.

[7] Jia Kang. Supply-side reform of the three issues [N]. Study Times, January 18, 2016 (4).

[8] Yang Hua. Deepening Physical Education Reform, Promoting the System of Sports Management and Modernization of Governance Capability [J]. Journal of Beijing Sport University, 2015, (1): 1-7.

[9] Dong Zhenhua. Category of Innovation and Innovation of Marxist Philosophy [J]. Journal of Jianghai University, 2015, (4): 39-44.

[10] Li Bo. Enlightenment of "Supply-side Reform" on the Development of Chinese Sports Industry - From the Perspective of New Supply Economics [J]. Acta Metallurgica Sinica, 2016, (2): 52-58. 